\title{
Effects of preweaning total plane of milk intake and weaning age on intake, growth performance, and blood metabolites of dairy calves
}

\author{
M. Mirzaei, ${ }^{*}$ N. Dadkhah,† B. Baghbanzadeh-Nobari,‡ A. Agha-Tehrani,† M. Eshraghi,† M. Imani,§ \\ R. Shiasi-Sardoabi,\# and M. H. Ghaffari $\|^{1,2}$ \\ *Department of Animal Science, Faculty of Agriculture and Natural Resources, Arak University, Arak 38156-88349, Iran \\ †Foudeh Dairy Complex, Isfahan 13895-81799, Iran \\ ‡Department of Nutrition 565, Ridley Corp. Ltd., Bourke Street, Melbourne, Victoria 3000, Australia \\ §Department of Animal Science, College of Agriculture and Natural Resources, University of Tehran, Karaj 3158711167-4111, Iran \\ \#Department of Animal Science, College of Agriculture, Isfahan University of Technology, Isfahan 84156-83111, Iran \\ IIDepartment of Agricultural, Food, and Nutritional Science, University of Alberta, Edmonton, T6G 2P5, Canada
}

\begin{abstract}
The objective of this study was to evaluate the effects of preweaning total plane of milk intake and weaning age on intake, growth performance, and blood metabolites of dairy calves. A total of 48 Holstein calves ( $40 \pm$ $1.6 \mathrm{~kg}$ of body weight) were used in a $2 \times 2$ factorial arrangement with the factors of weaning age (d 60 vs. 75$)$ and the total plane of milk intake (medium vs. high) during the preweaning period. Calves were assigned to 1 of 4 treatments: (1) calves fed medium plane of milk (MPM) intake and weaned on d 60 of age (MPM-60d, 4 $\mathrm{L} / \mathrm{d}$ of milk from d 3 to $10,6 \mathrm{~L} / \mathrm{d}$ of milk from d 11 to 55 , and $3 \mathrm{~L} / \mathrm{d}$ of milk from d 56 to 60 of age; total milk intake $=317 \mathrm{~L}),(2)$ calves fed MPM intake and weaned on d 75 of age (MPM-75d, 4 L/d of milk from d 3 to 10 and $4.5 \mathrm{~L} / \mathrm{d}$ of milk from d 11 to 70 of age followed by feeding $2.25 \mathrm{~L} / \mathrm{d}$ of milk from d 71 to 75 of age; total milk intake $=313 \mathrm{~L}),(3)$ calves fed high plane of milk (HPM) intake and weaned on d 60 of age (HPM-60d, $4 \mathrm{~L} / \mathrm{d}$ of milk from d 3 to $10,6 \mathrm{~L} / \mathrm{d}$ of milk from d 11 to 20 , and $8.5 \mathrm{~L} / \mathrm{d}$ of milk from d 21 to 55 followed by feeding $4.25 \mathrm{~L} / \mathrm{d}$ of milk from d 56 to 60 of age; total milk intake $=\sim 411 \mathrm{~L}$ ); and (4) calves fed HPM intake and weaned on d 75 (HPM-75d, 4 L/d of milk from d 3 to 10 , and $6 \mathrm{~L} / \mathrm{d}$ of milk from d 11 to 70 of age followed by feeding $3 \mathrm{~L} / \mathrm{d}$ of milk from d 71 to 75 of age; total milk intake $=407 \mathrm{~L}$ ) with no milk refusals. All of the calves were monitored up to d 90 of age. Regardless of weaning age, starter feed intake and dry matter in-
\end{abstract}

\footnotetext{
Received August 30, 2017.

Accepted January 6, 2018.

${ }^{1}$ Current position: Institute of Animal Science, Physiology \& Hygiene Unit, University of Bonn, Bonn 53115, Germany.

${ }^{2}$ Corresponding author: morteza1@uni-bonn.de
}

take (\% of body weight) were lower in calves fed HPM compared with those receiving MPM. A tendency for the plane of milk intake $\times$ weaning age interaction was observed for metabolizable energy intake with the highest value was recorded with the HPM-75d calves. The lowest efficiency of metabolizable energy intake and average feed efficiency was observed in HPM-60d calves throughout the experimental period as compared with the other groups. An interaction was found between the total plane of milk intake and weaning age regarding effects on total average daily gain, average daily gain/ metabolizable energy intake, feed efficiency, final body weight, and plasma $\beta$-hydroxybutyrate levels with the highest values measured in HPM-75d calves. Weaning on d 75 versus d 60 improved wither height and hip width, which tended to increase body length at the end of the trial. The results suggest that calves fed high amounts of milk during their preweaning period benefit from extending the time of weaning from 60 to $75 \mathrm{~d}$ of age based on average daily gain, feed efficiency, and final body weight.

Key words: calf, plane of milk, weaning age, growth

\section{INTRODUCTION}

Preweaning management of dairy calves over the past decade has been focused on alternative milk feeding methods in an attempt to improve dairy growth performance and health without adverse effects on rumen development (Eckert et al., 2015; Omidi-Mirzaei et al., 2015). The dairy industry has undergone a radical change from low to medium or high plane of milk intake in the feeding regimen, which is close to natural intakes and expectedly yields greater preweaning growth rates. Raising calves on a high plane of nutrition leads to many beneficial effects including greater ADG during their preweaning period (Jasper and Weary, 2002; Khan et al., 2007), earlier onset of puberty (Bar-Peled 
et al., 1997; Bartol et al., 2013), greater milk production in the first lactations (Moallem et al., 2010; Soberon et al., 2012), and fewer behavioral signs of hunger (de Passillé et al., 2011; Miller-Cushon and DeVries, 2015). Despite its benefits to growth performance, the high plane of milk intake ( $20 \% \mathrm{BW})$ is still not advised for the preweaning stage under all circumstances. The reason for this is that feeding excessive amounts of milk delays initiation of solid feed intake, which may compromise early rumen development in dairy calves (Appleby et al., 2001; Jasper and Weary, 2002). In support of this, Sweeney et al. (2010) found that calves fed large amounts of milk displayed not only decreased postweaning intake but also a weight loss during an abrupt weaning scheme at $40 \mathrm{~d}$ of age. This weight loss could be decreased by weaning at a later age (de Passillé et al., 2011), albeit it does increase the total amount of milk required.

The weaning strategy, especially weaning age, becomes increasingly important when greater volumes of milk are offered (Meale et al., 2015). The average weaning age of calves on dairy farms in the United States is $8.4 \mathrm{wk}$ (USDA, 2010). Extending weaning age when receiving high amounts of milk has been suggested to cope with the transition from milk to solid feed. Greater growth rates and more gut development at weaning were evident in dairy calves weaned at $8 \mathrm{wk}$ compared with those weaned at 6 wk of age, indicating that calves might benefit from a delayed weaning when fed the preweaning high plane of milk replacer (Eckert et al., 2015). Meale et al. (2015) found that, compared with those weaned at 8 wk, calves fed an elevated plane of milk replacer and weaned at 12 wk of age exhibited greater growth rates and reduced signs of stress during weaning. Bjorklund et al. (2013) also reported that calves weaned on d 30 of age had lower weight gains and body dimensions than those weaned on d 60 or 90 of age; however, by $120 \mathrm{~d}$ of age, all their calves had similar final BW. Total preweaning milk consumption and the timing of weaning are critical to dairy producers, although not enough investigation has been reported on determining the effect of weaning age on intake and growth performance when calves are fed different quantities of milk.

In this study, we hypothesized that dairy calves weaned at a later age (d 75) would have higher growth performance than those weaned at $60 \mathrm{~d}$ of age as a result of sufficient energy supplied by liquid feed and dry feed intakes when calves are fed higher quantities of milk. It is, therefore, the objective of this study to investigate the effects of preweaning total plane of milk intake (medium vs. high) on pre- and postweaning intake, growth performance, and blood metabolites of dairy calves weaned at different ages (d 60 vs. 75).

\section{MATERIALS AND METHODS}

\section{Experimental Treatments, Feeding, and Measurements}

This experiment was conducted on a local dairy farm (Fudeh Agriculture and Animal Husbandry, Isfahan, Iran) during the period September to October 2016. All the animal procedures were approved by the Animal Care Committee of Arak University by the Iranian Council of Animal Care (1995). A total of 48 Holstein dairy calves $(40 \pm 1.6 \mathrm{~kg}$ of $\mathrm{BW}, \mathrm{n}=12$ calves per treatment: 6 males and 6 females) were randomly assigned to 4 treatments in a $2 \times 2$ factorial arrangement with the factors of preweaning total plane of milk intake (medium vs. high) and weaning age (d 60 vs. 75 ). All the calves were housed from birth to d 90 of age in a naturally ventilated barn with individual pens (1.2 $\times 2.5 \mathrm{~m}$ ) bedded with sand that was renewed every 48 h. Calves were offered $4 \mathrm{~L}$ of colostrum using nipple bottles within $3 \mathrm{~h}$ of life and $12 \mathrm{~h}$ after the first feeding. The quality of colostrum was measured with a digital Brix refractometer (PAL-1, Atago Co. Ltd., Bellevue, WA) and discarded if measured lower than 22 on the Brix scale (Bielmann et al., 2010). If the dam produced colostrum of insufficient quality or quantity, frozen colostrum of sufficient quality was thawed and fed to the calf. From d 3 onward, milk containing $3.16 \pm 0.15 \%$ fat, $3.11 \pm 0.08 \% \mathrm{CP}, 4.55 \pm 0.09 \%$ lactose, and 11.30 $\pm 0.15 \%$ TS was fed individually in steel buckets in 2 meals of equal volumes per day (at 0800 and $1600 \mathrm{~h}$ ). Calves were assigned to 1 of 4 treatments (Figure 1): (1) calves fed medium plane of milk (MPM) intake and weaned on d 60 of age (MPM-60d, 4 L/d of milk from d 3 to 10, $6 \mathrm{~L} / \mathrm{d}$ of milk from d 11 to 55 , and $3 \mathrm{~L} / \mathrm{d}$ of milk from d 56 to 60 of age; total milk intake $=317$ L), (2) calves fed MPM intake and weaned on d 75 of age (MPM-75d, 4 L/d of milk from d 3 to 10 and 4.5 $\mathrm{L} / \mathrm{d}$ of milk from d 11 to 70 of age followed by $2.25 \mathrm{~L} / \mathrm{d}$ of milk from d 71 to 75 of age; total milk intake $=313$ L), (3) calves fed high plane of milk (HPM) intake and weaned on d 60 (HPM-60d, 4 L/d of milk from d 3 to $10,6 \mathrm{~L} / \mathrm{d}$ of milk from d 11 to 20 , and $8.5 \mathrm{~L} / \mathrm{d}$ of milk from d 21 to 55 followed by $4.25 \mathrm{~L} / \mathrm{d}$ of milk from d 56 to 60 of age; total milk intake $=\sim 411 \mathrm{~L}$ ); and (4) calves fed HPM intake and weaned on d 75 of age (HPM$75 \mathrm{~d}, 4 \mathrm{~L} / \mathrm{d}$ of milk from $\mathrm{d} 3$ to 10 and $6 \mathrm{~L} / \mathrm{d}$ of milk from d 11 to 70 of age followed by $3 \mathrm{~L} / \mathrm{d}$ of milk from $\mathrm{d}$ 71 to 75 of age; total milk intake $=407 \mathrm{~L}$ ); there were no refusals of milk. The study was terminated on d 90 . From d 1 to 90 of age, all the calves had free access to fresh water and a starter feed formulated according to the current NRC (2001). The ingredients and nutrient compositions of the starter feed are given in Table 1 . 


\section{- Pre-weaning \\ - - - Post-weaning}

Treatments

Total milk intake

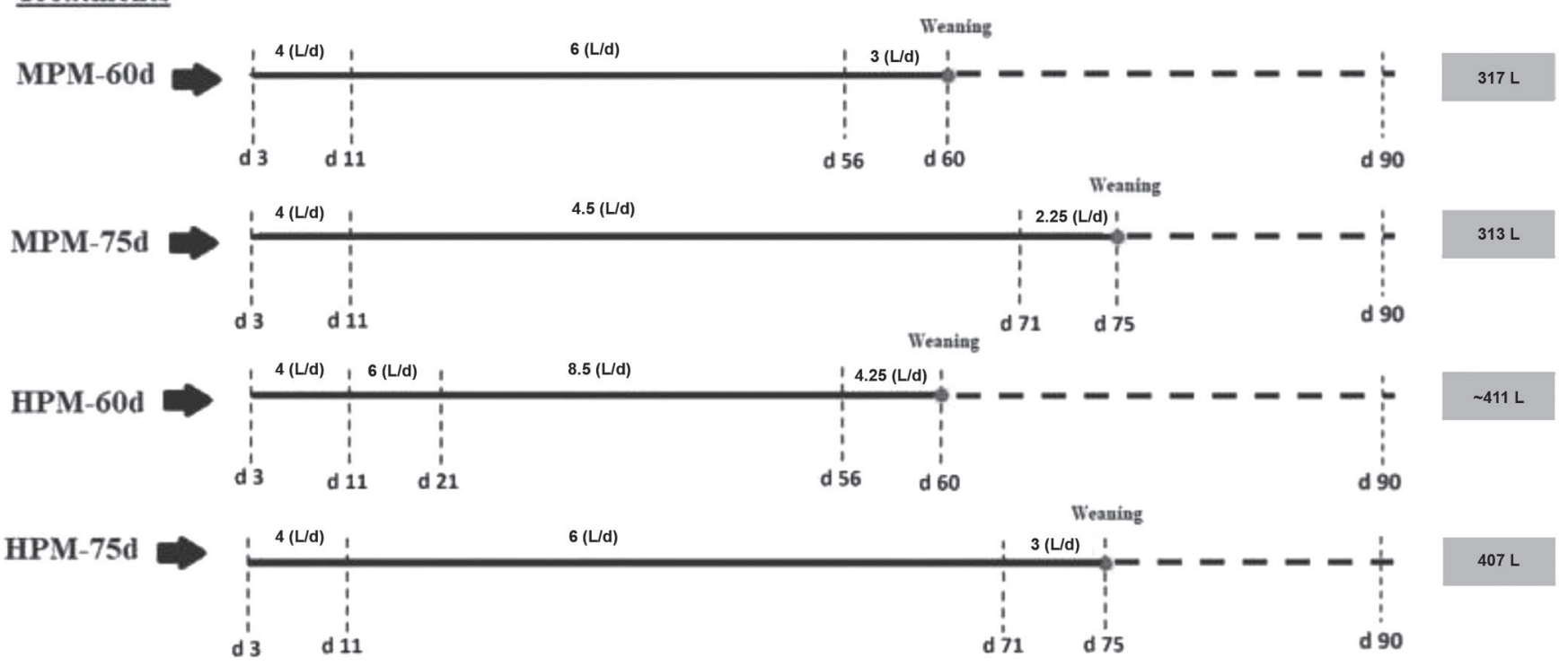

\section{Days of study}

Figure 1. The schematic diagram represents the amounts of milk consumed $(\mathrm{kg} / \mathrm{d})$ by calves on the different milk feeding programs and weaned at 60 or 75 d of age: MPM-60d (4 L/d of milk from d 3 to 10,6 L/d of milk from d 11 to 55 , and $3 \mathrm{~L} / \mathrm{d}$ of milk from d 56 to 60 of age; total milk intake $=317 \mathrm{~L})$, MPM-75d $(4 \mathrm{~L} / \mathrm{d}$ of milk from d 3 to 10 and $4.5 \mathrm{~L} / \mathrm{d}$ of milk from d 11 to 70 of age followed by $2.25 \mathrm{~L} / \mathrm{d}$ of milk from d 71 to 75 of age; total milk intake $=313 \mathrm{~L})$, HPM-60d $(4 \mathrm{~L} / \mathrm{d}$ of milk from d 3 to $10,6 \mathrm{~L} / \mathrm{d}$ of milk from d 11 to 20 , and $8.5 \mathrm{~L} / \mathrm{d}$ of milk from d 21 to 55 followed by $4.25 \mathrm{~L} / \mathrm{d}$ of milk from d 56 to 60 of age; total milk intake $=\sim 411 \mathrm{~L}$ ), and HPM-75d (4 L/d of milk from d 3 to 10 , and $6 \mathrm{~L} / \mathrm{d}$ of milk from d 11 to 70 of age followed by $3 \mathrm{~L} / \mathrm{d}$ of milk from d 71 to 75 of age; total milk intake $=407 \mathrm{~L}$ ).

Starter feeds were fed ad libitum to permit at least $10 \%$ orts (i.e., the portion of the starter not consumed over a 24-h period), and feed refusal from each individual calf was collected at $0730 \mathrm{~h}$. The treatment of disease followed the standard operating procedures at the Fudeh Agriculture, and Animal Husbandry Facility (Isfahan, Iran) and sick calves were treated by a veterinarian accordingly.

\section{Sample Collection and Analysis}

Amounts of starter feed offered were recorded daily and orts measured weekly. Metabolizable energy contents of the starter feed and milk were estimated using NRC equations (NRC, 2001). Intakes of ME were calculated by dividing that of each feed (starter or milk) by its ME content. Calves were weighed at the beginning of the experiment and every $10 \mathrm{~d}$ thereafter using an electronic balance to determine every $10-\mathrm{d}$ BW and ADG. Average daily gain and feed efficiency (FE, kg of BW gain $/ \mathrm{kg}$ of total DMI) were calculated. Body measurements including heart girth (circumference of the chest), body barrel (circumference of the belly before feeding), body length (distance between the points of shoulder and rump), hip width (distance between the points of hook bones), wither height (distance from base of the front feet to the withers), and hip height (distance from base of the rear feet to hook bones) of the calves were performed at the end of the study (d 90) according to the method described in Khan et al. (2007).

All the laboratory analyses were performed at the Laboratory of Analysis and Research, Department of Animal Science at Arak University, Arak, Iran. Weekly subsamples of feeds and refusals were mixed thoroughly, dried at $55^{\circ} \mathrm{C}$ for $48 \mathrm{~h}$, and ground to pass a $1-\mathrm{mm}$ screen in a Wiley mill (Ogaw Seiki Co. Ltd., Tokyo, Japan) before chemical analyses were performed for DM content (method 934.01, AOAC, 1990), ether extract (method 920.39, AOAC, 1990), CP (method 988.05, AOAC, 1990), ADF (AOAC, 1990: method 973.18), and NDF contents using a heat stable $\alpha$-amylase (100 $\mu \mathrm{L} / 0.5 \mathrm{~g}$ of the sample) with sodium sulfite (Van Soest et al., 1991). Ten representative samples of milk were 
collected throughout the study and analyzed for fat, $\mathrm{CP}$, lactose, and TS content using the Milkoscan (Foss Electric, Hillerød, Denmark; AOAC International, 2002).

Blood samples were collected $3 \mathrm{~h}$ after the morning meal on d 35 and 84 of age. Briefly, blood was withdrawn from the jugular vein into evacuated tubes containing $\mathrm{K}_{2}$ EDTA (Becton Dickinson Vacutainer Systems, Franklin Lakes, NJ) and immediately placed on ice. All the blood samples were centrifuged immediately at $3,000 \times g$ for $20 \mathrm{~min}$ at $4^{\circ} \mathrm{C}$ before 1.5 $\mathrm{mL}$ of the plasma was pipetted into $2-\mathrm{mL}$ cryotubes and stored immediately at $-20^{\circ} \mathrm{C}$ for subsequent analysis. Blood metabolite concentrations were spectrophotometrically (UNICCO, 2100; Zistchemi Co., Tehran, Iran) determined using commercially available kits [Pars Azmoon Company, Tehran, Iran; catalog numbers: glucose (1-500-017), albumin (1-500-001), total protein (1-500-028), alanine aminotransferase (ALT, 1-400-018), aspartate aminotransferase (AST, 1-400-019), and urea nitrogen (1-400-029)] according to the manufacturer's instructions. Plasma BHB was determined with the autoanalyzer using a laboratory kit (Randox Laboratories Ltd., Ardmore, UK).

Table 1. Ingredients and chemical composition of the experimental starter feed

\begin{tabular}{lc}
\hline Item & $\begin{array}{c}\text { \% of DM basis } \\
\text { (unless otherwise indicated) }\end{array}$ \\
\hline Ingredient & \\
Alfalfa hay & 10.00 \\
Corn grain, ground & 45.00 \\
Barley grain, ground & 14.00 \\
Soybean meal (45\% CP) & 26.75 \\
Energizer RP-10 1 & 1.25 \\
Vitamin and mineral mix ${ }^{2}$ & 0.50 \\
Sodium bicarbonate & 0.75 \\
Calcium carbonate & 1.25 \\
Salt & 0.50 \\
Chemical composition & \\
ME ${ }^{3}$ (Mcal/kg) & 3.28 \\
$\mathrm{NE}_{\mathrm{G}}{ }^{3}$ (Mcal/kg) & 1.57 \\
DM & 89.0 \\
$\mathrm{CP}^{\mathrm{E}}$ & 19.1 \\
$\mathrm{NDF}$ & 4.4 \\
$\mathrm{NFC}$ & 14.0 \\
$\mathrm{Ca}$ & 54.5 \\
$\mathrm{P}$ & 0.9 \\
\hline
\end{tabular}

${ }^{1}$ Prilled saturated free fatty acids (IFFCO, Johor Bahru, Malaysia). ${ }^{2}$ Contained per kilogram of supplement: 250,000 IU of vitamin A, $50,000 \mathrm{IU}$ of vitamin D, 1,500 IU of vitamin E, $2.25 \mathrm{~g}$ of Mn, $120 \mathrm{~g}$ of $\mathrm{Ca}, 7.7 \mathrm{~g}$ of $\mathrm{Zn}, 20 \mathrm{~g}$ of P, $20.5 \mathrm{~g}$ of $\mathrm{Mg}, 186 \mathrm{~g}$ of Na, $1.25 \mathrm{~g}$ of Fe, $3 \mathrm{~g}$ of S, $14 \mathrm{mg}$ of Co, $1.25 \mathrm{~g}$ of Cu, $56 \mathrm{mg}$ of I, and $10 \mathrm{mg}$ of Se.

${ }^{3}$ Calculated according to NRC (2001).

${ }^{4}$ Nonfiber carbohydrate was calculated as DM $-(\mathrm{NDF}+\mathrm{CP}+$ ether extract + ash) (NRC, 2001).

\section{Statistical Analysis}

Data were subjected to ANOVA using the MIXED procedure of SAS (PROC MIXED, SAS 9.3, SAS Institute Inc., Cary, NC) with time as repeated measures for starter feed intake, DMI, ME intake, BW, ADG, and FE with the individual calf as the experimental unit. The model included weaning age, the total plane of milk intake, and the interaction of weaning age $\times$ total plane of milk for all the data. Calf sex was tested as a main effect, but excluded from the final model because it was not significant. An autoregressive (order 1) covariance structure was chosen based on the Akaike and Bayesian information criteria. All the data were screened for normality using the UNIVARIATE procedure of SAS before analysis. Initial BW was used as a covariate for final weight. Skeletal growth (d 90) and blood metabolite (d 35 and 84) data were analyzed using the above model without the effect of time. Least squares means for treatment effects were separated using the PDIFF statement when the overall $F$-test was $P \leq 0.05$. Trends were declared when $P \leq 0.10$. Furthermore, the data on growth performance and blood metabolites were analyzed by principal components analysis (PCA) using the PRINCOMP Procedure of SAS to visually identify differences among the treatment groups.

\section{RESULTS AND DISCUSSION}

\section{Intake and Growth Performance}

As provisioned, HPM-60d and HPM-75d calves consumed more milk than those in the MPM-60d and MPM-75d calves during the milk feeding period (Figure 1). No significant interactions were observed between the plane of milk intake and weaning age for starter feed intake $(\mathrm{kg} / \mathrm{d})$ and total starter intake (d 3 to 90). However, regardless of weaning age, intakes of starter feed were greater $(P<0.001)$ in MPM calves than in HPM ones (Table 2). Average DMI (kg/d; starter DM + milk DM) exhibited no differences across the treatments (Table 2). Regardless of weaning age, average DMI (2.11 vs. $2.02 \%$ of BW) was greater $(P=0.02)$ in the MPM calves than it was in the HPM treatment (Table 2). It has been established that solid feed intake is inversely correlated with milk intake and that offering high milk during the preweaning period results in inadequate solid feed intake for weaning (de Passillé et al., 2011; Miller-Cushon et al., 2013; de Paula et al., 2017; Rosenberger et al., 2017). It is important to encourage early intake of calf starter to promote rumen development and function in the neonatal calf. In this study, MPM calves that were fed less milk probably attempted to compensate for the lower supply of nutri- 
Table 2. Effects of preweaning total plane of milk intake [M; medium plane of milk intake (MPM) vs. high plane of milk intake (HPM)] and preweaning and weaning age (W; 60 vs. 75 d) on starter intake, DMI, ME intake, ADG, and feed efficiency (FE) of dairy calves (n = 12 calves per treatment)

\begin{tabular}{|c|c|c|c|c|c|c|c|c|}
\hline Item & \multicolumn{4}{|c|}{ Treatment $^{1}$} & SEM & \multicolumn{3}{|c|}{$P$-value } \\
\hline Starter intake $(\mathrm{kg} / \mathrm{d})$ & 1.42 & 1.37 & 1.15 & 1.23 & 0.04 & $<.0001$ & 0.62 & 0.11 \\
\hline Average $\mathrm{DMI}^{2}(\mathrm{~d} 3-90 ; \mathrm{kg} / \mathrm{d})$ & 1.72 & 1.67 & 1.60 & 1.68 & 0.04 & 0.26 & 0.77 & 0.16 \\
\hline Average $\mathrm{DMI}^{2}$ (d 3-90; \% of BW) & 2.14 & 2.08 & 2.01 & 2.04 & 0.04 & 0.02 & 0.71 & 0.22 \\
\hline Total ME intake (d 3 to $90 ;$ Mcal) & 590 & 573 & 578 & 601 & 13.6 & 0.55 & 0.82 & 0.16 \\
\hline ADG/ME intake (d 3-90; g/Mcal) & 0.14 & 0.14 & 0.13 & 0.15 & 0.01 & 0.28 & 0.14 & 0.04 \\
\hline Average $\mathrm{FE}^{3}(\mathrm{~d} 3-90)$ & 0.63 & 0.60 & 0.57 & 0.64 & 0.02 & 0.74 & 0.26 & 0.04 \\
\hline
\end{tabular}

${ }^{1}$ Treatments: (1) calves were offered MPM intake and weaned on d 60 (MPM-60d; total milk intake $\left.=317 \mathrm{~L}\right),(2)$ calves were offered MPM intake and weaned on d $75($ MPM-75d; total milk intake $=313)$, (3) calves were offered HPM intake and weaned on d 60 (HPM-60d; total milk intake $=\sim 411)$; and $(4)$ calves were offered HPM intake and weaned on d 75 (HPM-75d; total milk intake $=407)$.

${ }^{2} \mathrm{DMI}=$ starter $\mathrm{DM}+$ milk DM.

${ }^{3}$ Feed efficiency was calculated by dividing ADG (g) by average daily DMI.

ents by consuming more starter feed. Results regarding starter feed intake herein are in line with those reported by de Paula et al. (2017) who reported more starter feed consumed during the preweaning period by calves fed low levels of milk. A lower solid feed intake was observed in the HPM-60d calves in the present experiment, which led to an inadequate starter feed intake (less than $800 \mathrm{~g} / \mathrm{d}$; Quigley, 1996) in the weaning dairy calves.

Comparison of weaning on d 60 and 75 might imply the investigation of not only an effect of the duration of milk feeding but also an effect of a different physiological age. Because a change in weaning age is coupled with a change in physiological age, it has to be kept in mind that all measured parameters may be affected both by the duration of the milk feeding period and the physiological age. In the current study, weaning caused a significant increase in starter feed intake in all the calves, regardless of their weaning age. An increase in starter intake immediately after weaning is in accordance with previous studies (Sweeney et al., 2010; de Paula et al., 2017). In the current study, calves in all the groups consumed more than $2.6 \mathrm{~kg} / \mathrm{d}$ of starter feed during their postweaning period, showing that all the calves received sufficient starter feed to compensate for the likely loss of nutrients from the milk. This finding demonstrates that although HPM-60d calves did not have adequate solid feed intake during their preweaning period, their starter feed intake increased rapidly after weaning. However, treatment differences in starter intake disappeared after weaning transition (d 80 and 90 of age). In line with our findings, Dennis et al. (2018) reported that feeding $0.66 \mathrm{~kg}$ of $\mathrm{DM} / \mathrm{d}$ from a milk replacer and weaning at $6 \mathrm{wk}$ of age resulted in starter intakes in dairy calves through 4 mo of age similar to those observed with milk replacer programs feeding up to $1.1 \mathrm{~kg}$ of DM/d and weaning at 8 wk of age. Eckert et al. (2015) also found a weaning age effect on starter intake of dairy calves, but the difference in overall starter intakes between the groups (weaning at 6 or 8 wk of age) disappeared during the last week of the experiment (63-70 d of life). It is, therefore, necessary to identify the long-term implications of these feeding practices on calf performance.

An interaction was found between the plane of milk intake and weaning age regarding their effects on total ADG (d 3 to $90, P=0.03$ ) with the highest and lowest total weight gains observed in the HPM-75d and HPM-60d calves, respectively (Table 2). As hypothesized, the calves on the HPM diet could be successfully weaned from milk with better weight gains when weaning was delayed from 60 to $75 \mathrm{~d}$. Our results are in agreement with those of de Passillé and Rushen (2012), who reported that calves fed HPM $(12 \mathrm{~L} / \mathrm{d})$ and weaned later (12 vs. $8 \mathrm{wk}$ ) had greater ADG during their weaning period (0.5 vs. $1.0 \mathrm{~kg} / \mathrm{d}$ ). Eckert et al. (2015) also showed that delayed weaning promoted beneficial effects on intake and growth in dairy cows during their weaning and thereafter. This delay in weaning clearly facilitated a more gradual shift in microbial diversity in both the rumen and feces of the dairy calves when feeding a high plane of preweaning nutrition (Meale et al., 2017).

Total ME intakes (d 3 to 90 of age) did not differ among treatment, whereas a tendency $(P=0.07)$ was observed for ME intake in the plane of milk intake $\times$ weaning age interaction (Table 2). The ME intake (g/Mcal) and average FE (d 3 to 90 of age) exhibited their lowest efficiencies in the HPM-60d calves compared with other groups throughout the experiment $(P$ 
$=0.04$, Table 2). These results showed that average $\mathrm{FE}$ and $\mathrm{ADG} / \mathrm{ME}$ intake depended on weaning age, especially when milk was fed at high levels.

No differences were observed in initial BW (d 3 of age) among the treatments (Table 3). An interaction was found between the plane of milk intake and weaning age regarding their effects on final BW $(P$ $=0.04)$, with the highest total weight gain observed in the HPM-75d calves (Table 3). Weaning on $\mathrm{d} 75$ versus d 60 improved wither height $(1.8 \mathrm{~cm} ; P=0.03)$ and hip width $(1 \mathrm{~cm} ; P=0.04)$, and it also tended to increase body length $(1.1 \mathrm{~cm} ; P=0.09)$ at the end of the trial (Table 3). Moreover, no differences were observed in heart girth and hip height among the treatments (Table 3). In line with this finding, Eckert et al. (2015) reported that calves fed an HPM during their preweaning period had greater weaning and final BW when weaning was extended from 6 to 8 wk of age. Meale et al. (2015) also showed a growth advantage in BW between the calves weaned at 8 and 12 wk of age, indicating that calves might benefit from a delayed weaning when fed a preweaning HPM. However, limited research exists regarding longer-term growth advantages of delayed weaning such that further research is warranted to shed more light on this seemingly critical period.

\section{Blood Metabolites}

On d 30 of age, a trend $(P=0.06)$ observed for the plasma glucose concentration to be greater in the HPM calves than in the MPM calves, although no differences were detected among the treatments on $\mathrm{d} 84$ (Table 4). In agreement with previous reports (Lee et al., 2009; Omidi-Mirzaei et al., 2015), plasma glucose concentrations decreased with age in calves assigned to different milk-feeding programs, indicating a normal physiological shift in the source of energy from glu- cose to short-chain fatty acids with the initiation of ruminal fermentation and development (Khan et al., 2008). Plasma glucose level was found to be greater in calves fed HPM intake during their postprandial measurements, confirming previous findings (Terré et al., 2009; MacPherson et al., 2016). This is expected as HPM calves received greater levels of dietary lactose that have been reported to increase blood glucose concentration (Palmquist et al., 1992).

As expected, an age effect for BHB concentrations (Table 4) was observed as a result of the increase in solid feed consumption and the associated rumen development (Nemati et al., 2015; de Paula et al., 2017). No differences were detected in plasma BHB levels among the treatments on d 35 of age (Table 4). On d 84 of age, however, an interaction was detected between the plane of milk intake and the weaning age regarding their effects on plasma BHB levels, with the highest $(P=0.01)$ value recorded in the HPM-75d and MPM-60d calves (Table 4). Increasing plasma BHB levels might indicate elevated hepatic ketogenesis perhaps due to a ruminal supply of butyrate or reduced oxidation of fatty acids from body fat mobilization (Kesser et al., 2017). Contrary to our expectation, plasma BHB concentrations did not differ in calves allocated to the MPM-75d and HPM-75d treatments; both groups, however, exhibited lower values than did the HPM-75d and MPM-60d groups. This finding might indicate the beneficial effects of feeding medium levels of milk per day on rumen development in dairy calves. Recently, Suarez-Mena et al. (2017) reported that solid feed intake is not the only factor influencing blood BHB in dairy cows and other items such as stress, weaning, and intake restriction might influence blood BHB concentrations. Thus, further research is required by the dairy industry to properly assess and determine the long-term implications of moderate levels of milk feeding on the biological outcomes later in life.

Table 3. Effects of preweaning total plane of milk intake [M; the medium plane of milk intake (MPM) vs. high plane of milk intake (HPM)] and weaning age (W; 60 vs. $75 \mathrm{~d})$ on $\mathrm{BW}$ and structural growth of dairy calves $(\mathrm{n}=12$ calves per treatment)

\begin{tabular}{|c|c|c|c|c|c|c|c|c|}
\hline \multirow[b]{2}{*}{ Item } & \multicolumn{4}{|c|}{ Treatment $^{1}$} & \multirow[b]{2}{*}{ SEM } & \multicolumn{3}{|c|}{$P$-value } \\
\hline & MPM-60d & $\mathrm{MPM}-75 \mathrm{~d}$ & HPM-60d & HPM-75d & & $\mathrm{M}$ & $\mathrm{W}$ & $\mathrm{M} \times \mathrm{W}$ \\
\hline Final BW (d 90; kg) & 114.9 & 114.7 & 112.9 & 121.2 & 1.96 & 0.26 & 0.04 & 0.04 \\
\hline Heart girth $(\mathrm{d} 90 ; \mathrm{cm})$ & 112.0 & 108.4 & 109.0 & 108.6 & 1.4 & 0.32 & 0.16 & 0.25 \\
\hline Body barrel $(\mathrm{d} 90 ; \mathrm{cm})$ & 136.2 & 132.2 & 133.8 & 135.4 & 1.6 & 0.83 & 0.46 & 0.15 \\
\hline Body length $(\mathrm{d} 90 ; \mathrm{cm})$ & 67.2 & 67.7 & 66.2 & 67.9 & 0.6 & 0.50 & 0.09 & 0.35 \\
\hline Hip height $(\mathrm{d} 90 ; \mathrm{cm})$ & 104.0 & 103.9 & 101.4 & 104.0 & 0.7 & 0.10 & 0.10 & 0.11 \\
\hline
\end{tabular}

\footnotetext{
${ }^{1}$ Treatments: (1) Calves were offered MPM intake and weaned on d 60 (MPM-60d; total milk intake $=317 \mathrm{~L}$ ), (2) calves were offered MPM intake and weaned on d 75 (MPM-75d; total milk intake $=313)$, (3) calves were offered HPM intake and weaned on d 60 (HPM-60d; total milk intake $=\sim 411$ ); and (4) calves were offered HPM intake and weaned on d 75 (HPM-75d; total milk intake $=407)$.
} 
Plasma concentrations of AST, albumin, and total protein were not affected by the treatments (Table 4). Weaning delayed from d 60 to 75 of age decreased the plasma levels of ALT in dairy calves (Table 4). The examination of the individual samples indicated that there was no abnormal hepatic disease in the calves. On d 84 of age, an interaction tendency was found between the plane of milk intake and weaning age regarding their effects on plasma urea concentration, with the lowest $(P=0.10)$ value recorded for the HPM-60d calves (Table 4). Bartlett et al. (2006) reported that feeding high plane of milk replacer catabolizes fewer $\mathrm{AA}$ in the body, resulting in lower plasma urea $\mathrm{N}$ in intensively milk-fed calves. Schäff et al. (2016) also reported a reduction in plasma urea concentrations in calves fed ad libitum milk replacer compared with restricted calves. Overall, no metabolic benefits were observed from the intensive feeding of milk when calves were weaned on d 60 of age.

\section{Principal Components Analysis}

Figure 2 presents the main results of PCA performed using the mean values obtained for all the traits measured in this study on dairy calves subjected to different milk feeding programs (A), total plane of milk intake (315 or $409 \mathrm{~L}$ ) received during the milk feeding period
(B), and the different weaning ages (C; d 60 vs. 75). Principal component (PC) 1 and PC2 explained 22.5 and $17.7 \%$ of the total variance, respectively. The results from the PCA (Figure 2A) shows 3 clusters of the growing calves fed milk through different milk-feeding programs; the results correlated with the planes of milk offered per day. As can be observed in Figure 2A, the MPM-60d groups were much closer to the HPM-75d group, whereas PC1 placed the MPM-75d and HPM$60 \mathrm{~d}$ groups on opposite sides. The potential for an optimal level of feeding milk to achieve greater postweaning BW, therefore, appears to depend on sufficient solid feed intake during the preweaning period, which can be encouraged when weaning is extended from 60 to $75 \mathrm{~d}$ of age.

\section{CONCLUSIONS}

Feeding greater volumes of milk increased the ME intake in calves during their milk feeding stage but impaired their total solid feed intake. The results of this study suggest that calves fed greater volumes of milk during their preweaning stage and weaned later in life (d 75) had greater overall weight gain and FE compared with those weaned on d 60 of age. Final BW was greater in calves fed HPM when weaned on d 75 compared with the other groups. In summary, the re-

Table 4. Effects of preweaning total plane of milk intake [M; the medium plane of milk intake (MPM) vs. high plane of milk intake (HPM)] and weaning age (W; 60 vs. $75 \mathrm{~d})$ on blood metabolites of dairy calves $(\mathrm{n}=12$ calves per treatment)

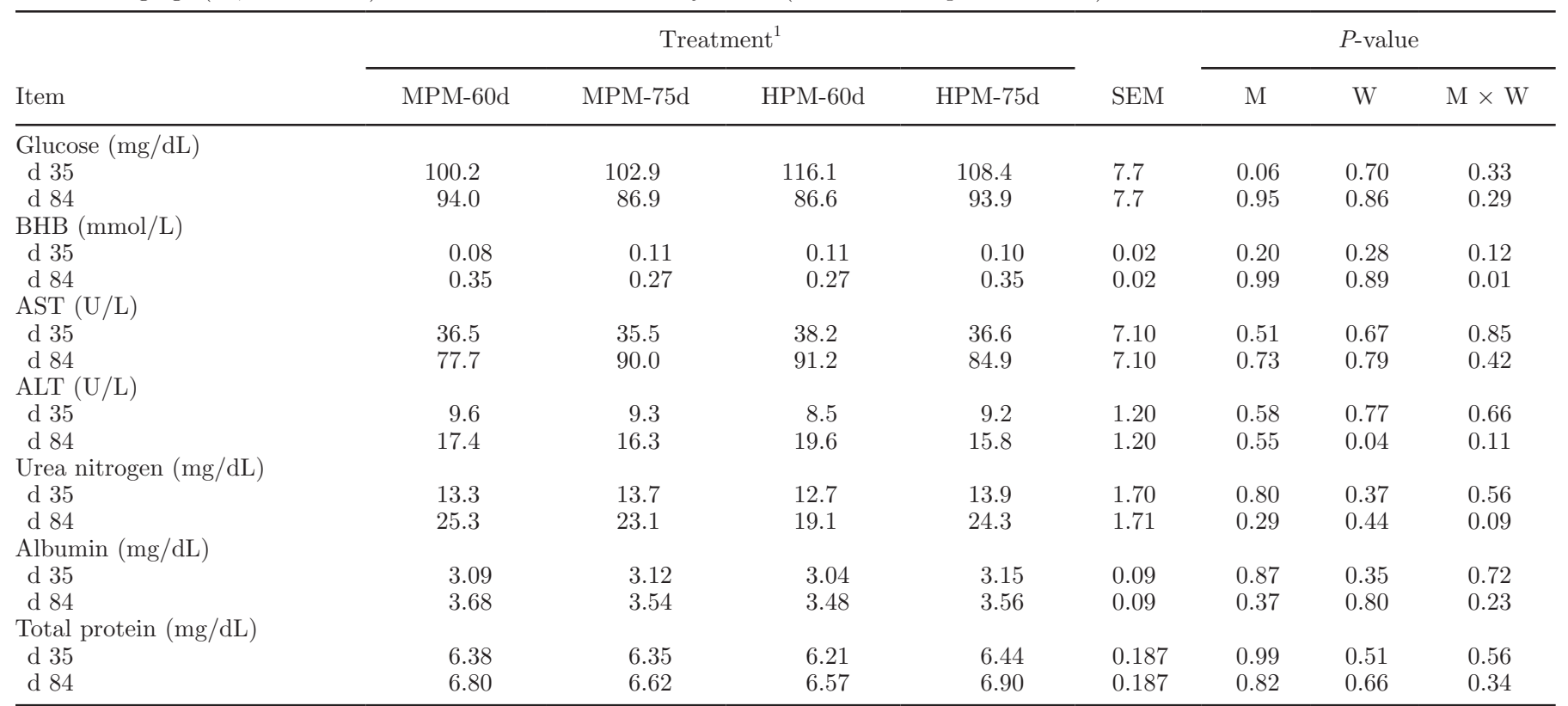

${ }^{1}$ Treatments: (1) Calves were offered MPM intake and weaned on d 60 (MPM-60d; total milk intake $=317 \mathrm{~L}$ ), (2) calves were offered MPM intake and weaned on d 75 (MPM-75d; total milk intake = 313), (3) calves were offered HPM intake and weaned on d 60 (HPM-60d; total milk intake $=\sim 411$ ); and (4) calves were offered HPM intake and weaned on d 75 (HPM-75d; total milk intake $=407)$. 

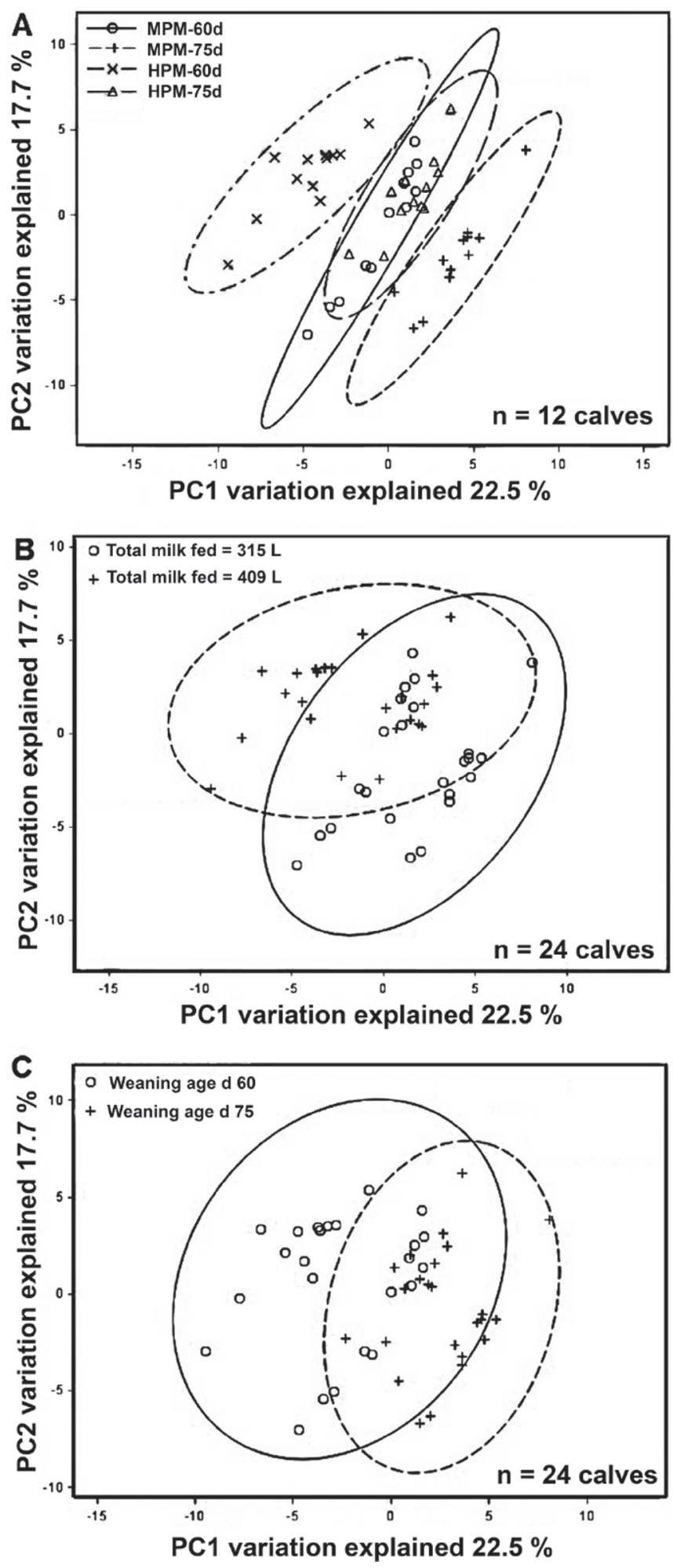

Figure 2. Principal component analysis using the mean values obtained for all the traits measured in this study of dairy calves fed different levels of preweaning milk and weaned at different ages (A), total plane of milk intake (medium vs. high) received during the milk feeding period (B), and the different weaning ages (C; d 60 vs. d 75). Percentages of explained variances for principal component (PC) 1 and $\mathrm{PC} 2$ are 22.5 and $17.7 \%$, respectively. sults of this study confirm our original hypothesis that feeding HPM may offer calf growth advantages depending on weaning age.

\section{ACKNOWLEDGMENTS}

The authors acknowledge Arak University for the financial support of this study. Further, the help of Mohamad-Ali Foudeh and Abolfazl Soltani for providing the facilities and the help of the staff (Neda Tadayonian, Yadollah Moharrami, Monireh Mehrabi, and Fatemeh Sfarzadeh) at the cattle facility for animal care was gratefully acknowledged.

\section{REFERENCES}

AOAC. 1990. Official Methods of Analysis. 15th ed. Association of Official Analytical Chemists, Arlington, VA.

AOAC International. 2002. Official Methods of Analysis. 17th ed. AOAC International, Arlington, VA.

Appleby, M. C., D. M. Weary, and B. Chua. 2001. Performance and feeding behaviour of calves on ad libitum milk from artificial teats. Appl. Anim. Behav. Sci. 74:191-201. https://doi.org/10.1016/ S0168-1591(01)00171-X.

Bar-Peled, U., B. Robinzon, E. Maltz, H. Tagari, Y. Folman, I. Bruckental, H. Voet, H. Gacitua, and A. R. Lehrer. 1997. Increased weight gain and effects on production parameters of Holstein heifer calves that were allowed to suckle from birth to six weeks of age. J. Dairy Sci. 80:2523-2528. https://doi.org/10.3168/jds.S0022 $-0302(97) 76205-2$.

Bartlett, K. S., F. K. McKeith, M. J. VandeHaar, G. E. Dahl, and J. K. Drackley. 2006. Growth and body composition of dairy calves fed milk replacers containing different amounts of protein at two feeding rates. J. Anim. Sci. 84:1454-1467. https://doi.org/10 $.2527 / 2006.8461454$.

Bartol, F. F., A. A. Wiley, D. J. Miller, A. J. Silva, K. E. Roberts, M. L. P. Davolt, J. C. Chen, A. L. Frankshun, M. E. Camp, K. M. Rahman, J. L. Vallet, and C. A. Bagnell. 2013. Lactation Biology Symposium: Lactocrine signaling and developmental programming. J. Anim. Sci. 91:696-705. https://doi.org/10.2527/jas.2012 -5764 .

Bielmann, V., J. Gillan, N. R. Perkins, A. L. Skidmore, S. Godden, and K. E. Leslie. 2010. An evaluation of Brix refractometry instruments for measurement of colostrum quality in dairy cattle. J. Dairy Sci. 93:3713-3721. https://doi.org/10.3168/jds.2009-2943.

Bjorklund, E. A., B. J. Heins, and H. Chester-Jones. 2013. Whole-milk feeding duration, calf growth, and profitability of group-fed calves in an organic production system. J. Dairy Sci. 96:7363-7370. https://doi.org/10.3168/jds.2013-6772.

de Passillé, A. M., T. F. Borderas, and J. Rushen. 2011. Weaning age of calves fed a high milk allowance by automated feeders: Effects on feed, water, and energy intake, behavioral signs of hunger, and weight gains. J. Dairy Sci. 94:1401-1408. https://doi.org/10.3168/ jds.2010-3441.

de Passillé, A. M., and J. Rushen. 2012. Adjusting the weaning age of calves fed by automated feeders according to individual intakes of solid feed. J. Dairy Sci. 95:5292-5298. https://doi.org/10.3168/ jds.2012-5521.

de Paula, M. R., C. E. Oltramari, J. T. Silva, M. P. C. Gallo, G. B. Mourão, and C. M. M. Bittar. 2017. Intensive liquid feeding of dairy calves with a medium crude protein milk replacer: Effects on performance, rumen, and blood parameters. J. Dairy Sci. 100:4448-4456. https://doi.org/10.3168/jds.2016-10859.

Dennis, T. S., F. X. Suarez-Mena, T. M. Hill, J. D. Quigley, R. L. Schlotterbeck, and L. Hulbert. 2018. Effect of milk replacer feeding rate, age at weaning, and method of reducing milk replacer to 
weaning on digestion, performance, rumination, and activity in dairy calves to 4 months of age. J. Dairy Sci. 101:268-278. https:/ doi.org/10.3168/jds.2017-13692.

Eckert, E., H. E. Brown, K. E. Leslie, T. J. DeVries, and M. A. Steele 2015. Weaning age affects growth, feed intake, gastrointestinal development, and behavior in Holstein calves fed an elevated plane of nutrition during the preweaning stage. J. Dairy Sci. 98:6315-6326. https://doi.org/10.3168/jds.2014-9062.

Iranian Council of Animal Care. 1995. Guide to the Care and Use of Experimental Animals, Vol. 1. Isfahan University of Technology, Isfahan, Iran.

Jasper, J., and D. M. Weary. 2002. Effects of ad-libitum milk intake on dairy calves. J. Dairy Sci. 85:3054-3058. https://doi.org/10.3168/ jds.S0022-0302(02)74391-9.

Kesser, J., M. Korst, C. Koch, F. J. Romberg, J. Rehage, U. Müller, M. Schmicke, K. Eder, H. M. Hammon, H. Sadri, and H. Sauerwein. 2017. Different milk feeding intensities during the first 4 weeks of rearing dairy calves: Part 2: Effects on the metabolic and endocrine status during calfhood and around the first lactation. J. Dairy Sci. 100:3109-3125. https://doi.org/10.3168/jds.2016-11595.

Khan, M. A., H. J. Lee, W. S. Lee, H. S. Kim, K. S. Ki, T. Y. Hur, G. H. Suh, S. J. Kang, and Y. J. Choi. 2007. Structural growth, rumen development, metabolic and immune response of Holstein male calves fed milk through step-down and conventional methods. J. Dairy Sci. 90:3376-3387. https://doi.org/10.3168/jds.2007 -0104 .

Khan, M. A., H. J. Lee, W. S. Lee, H. S. Kim, S. B. Kim, S. B. Park, K. S. Baek, J. K. Ha, and Y. J. Choi. 2008. Starch source evaluation in calf starter: II. Ruminal parameters, rumen development, nutrient digestibilities, and nitrogen utilization in Holstein calves. J. Dairy Sci. 91:1140-1149. https://doi.org/10.3168/jds.2007-0337.

Lee, H. J., M. A. Khan, W. S. Lee, S. H. Yang, S. B. Kim, K. S. Ki, H. S. Kim, J. K. Ha, and Y. J. Choi. 2009. Influence of equalizing the gross composition of milk replacer to that of whole milk on the performance of Holstein calves. J. Anim. Sci. 87:1129-1137. https://doi.org/10.2527/jas.2008-1110.

MacPherson, J. A. R., H. Berends, L. N. Leal, J. P. Cant, J. MartínTereso, and M. A. Steele. 2016. Effect of plane of milk replacer intake and age on glucose and insulin kinetics and abomasal emptying in female Holstein Friesian dairy calves fed twice daily. J Dairy Sci. 99:8007-8017. https://doi.org/10.3168/jds.2015-10826.

Meale, S. J., L. N. Leal, J. Martin-Tereso, and M. A. Steele. 2015. Delayed weaning of Holstein bull calves fed an elevated plane of nutrition impacts feed intake, growth and potential markers of gastrointestinal development. Anim. Feed Sci. Technol. 209:268-273. https://doi.org/10.1016/j.anifeedsci.2015.08.008.

Meale, S. J., S. C. Li, P. Azevedo, H. Derakhshani, T. J. DeVries, J. C. Plaizier, M. A. Steele, and E. Khafipour. 2017. Weaning age influences the severity of gastrointestinal microbiome shifts in dairy calves. Sci. Rep. 7:198-211. https://doi.org/10.1038/s41598 -017-00223-7.

Miller-Cushon, E. K., R. Bergeron, K. E. Leslie, and T. J. DeVries. 2013. Effect of milk feeding level on development of feeding behavior in dairy calves. J. Dairy Sci. 96:551-564. https://doi.org/10 $.3168 /$ jds.2012-5937.

Miller-Cushon, E. K., and T. J. DeVries. 2015. Invited review: Development and expression of dairy calf feeding behaviour. Can. J. Anim. Sci. 95:1-10. https://doi.org/10.4141/cjas-2014-163.

Moallem, U., D. Werner, H. Lehrer, M. Zachut, L. Livshitz, S. Yakoby, and A. Shamay. 2010. Long-term effects of ad libitum whole milk prior to weaning and prepubertal protein supplementation on skeletal growth rate and first-lactation milk production. J. Dairy Sci. 93:2639-2650. https://doi.org/10.3168/jds.2009-3007.
Nemati, M., H. Amanlou, M. Khorvash, B. Moshiri, M. Mirzaei, M A. Khan, and M. H. Ghaffari. 2015. Rumen fermentation, blood metabolites, and growth performance of calves during transition from liquid to solid feed: Effects of dietary level and particle size of alfalfa hay. J. Dairy Sci. 98:7131-7141. https://doi.org/10.3168/ jds.2014-9144.

NRC. 2001. Nutrient Requirement of Dairy Cattle. 7th rev. ed. Natl. Acad. Sci., Washington, DC.

Omidi-Mirzaei, H., M. Khorvash, G. R. Ghorbani, B. Moshiri, M. Mirzaei, A. Pezeshki, and M. H. Ghaffari. 2015. Effects of the step-up/step-down and step-down milk feeding procedures on the performance, structural growth, and blood metabolites of Holstein dairy calves. J. Dairy Sci. 98:7975-7981. https://doi.org/10.3168/ jds.2014-9260

Palmquist, D. L., K. L. Roehrig, D. J. Kinsey, and J. Doppenberg. 1992. Glucose and insulin metabolism in ruminating and veal calves fed high and low fat diets. Domest. Anim. Endocrinol. 9:233-241. https://doi.org/10.1016/0739-7240(92)90037-X.

Quigley, J. D. 1996. Feeding prior to weaning. Pages 245-255 in Calves, Heifers and Dairy Profitability. Facilities, Nutrition, and Health (ed. sine nomine). Northeast Regional Agricultural Engineering Service, Cooperative Extension, Ithaca, NY.

Rosenberger, K., J. H. C. Costa, H. W. Neave, M. A. G. von Keyserlingk, and D. M. Weary. 2017. The effect of milk allowance on behavior and weight gains in dairy calves. J. Dairy Sci. 100:504-512. https://doi.org/10.3168/jds.2016-11195.

Schäff, C. T., J. Gruse, J. Maciej, M. Mielenz, E. Wirthgen, A Hoeflich, M. Schmicke, R. Pfuhl, P. Jawor, T. Stefaniak, and H. M. Hammon. 2016. Effects of feeding milk replacer ad libitum or in restricted amounts for the first five weeks of life on the growth, metabolic adaptation, and immune status of newborn calves. PLoS One 11:e0168974. https://doi.org/10.1371/journal.pone.0168974.

Soberon, F., E. Raffrenato, R. W. Everett, and M. E. Van Amburgh. 2012. Preweaning milk replacer intake and effects on long-term productivity of dairy calves. J. Dairy Sci. 95:783-793. https://doi .org/10.3168/jds.2011-4391.

Suarez-Mena, F. X., W. Hu, T. S. Dennis, T. M. Hill, and R. L. Schlotterbeck. 2017. $\beta$-Hydroxybutyrate (BHB) and glucose concentrations in the blood of dairy calves as influenced by age, vaccination stress, weaning, and starter intake including evaluation of $\mathrm{BHB}$ and glucose markers of starter intake. J. Dairy Sci. 100:2614-2624. https://doi.org/10.3168/jds.2016-12181.

Sweeney, B. C., J. Rushen, D. M. Weary, and A. M. de Passillé. 2010 Duration of weaning, starter intake, and weight gain of dairy calves fed large amounts of milk. J. Dairy Sci. 93:148-152. https:// doi.org/10.3168/jds.2009-2427.

Terré, M., C. Tejero, and A. Bach. 2009. Long-term effects on heifer performance of an enhanced-growth feeding programme applied during the preweaning period. J. Dairy Res. 76:331-339. https:/ doi.org/10.1017/S0022029909004142.

USDA. 2010. Dairy 2007, heifer calf health and management practices on U.S. Dairy Operations, 2007. USDA: APHIS:VS, CEAH, National Animal Health Monitoring System, Fort Collins, CO. \#550.0110. Accessed Sep. 21, 2015. https://www.aphis.usda .gov/animal_health/nahms/dairy/downloads/dairy07/Dairy07_ir CalfHealth.pdf.

Van Soest, P. J., J. B. Robertson, and B. A. Lewis. 1991. Methods for dietary fiber, neutral detergent fiber nonstarch polysaccharide in relation to animal nutrition. J. Dairy Sci. 74:3583-3597. https:// doi.org/10.3168/jds.S0022-0302(91)78551-2. 